\title{
Pre-operational short-term forecasts for Mediterranean Sea biogeochemistry
}

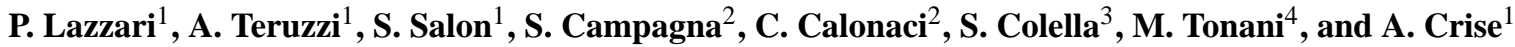 \\ ${ }^{1}$ Istituto Nazionale di Oceanografia e di Geofisica Sperimentale, Sgonico, Italy \\ ${ }^{2}$ CINECA, Casalecchio di Reno, Italy \\ ${ }^{3}$ ISAC-CNR, Roma, Italy \\ ${ }^{4}$ Istituto Nazionale di Geofisica e Vulcanologia, Bologna, Italy
}

Received: 1 June 2009 - Published in Ocean Sci. Discuss.: 29 June 2009

Revised: 25 November 2009 - Accepted: 28 December 2009 - Published: 21 January 2010

\begin{abstract}
Operational prediction of the marine environment is recognised as a fundamental research issue in Europe. We present a pre-operational implementation of a biogeochemical model for the pelagic waters of the Mediterranean Sea, developed within the framework of the MERSEA-IP European project. The OPATM-BFM coupled model is the core of a fully automatic system that delivers weekly analyses and forecast maps for the Mediterranean Sea biogeochemistry. The system has been working in its current configuration since April 2007 with successful execution of the fully automatic operational chain in $87 \%$ of the cases while in the remaining cases the runs were successfully accomplished after operator intervention. A description of the system developed and also a comparison of the model results with satellite data are presented, together with a measure of the model skill evaluated by means of seasonal target diagrams. Future studies will address the implementation of a data assimilation scheme for the biogeochemical compartment in order to increase the skill of the model's performance.
\end{abstract}

\section{Introduction}

Environmental risks of natural or anthropogenic origin may be prevented or managed by using short-term forecasts such those provided by an operational forecasting system. In this regard, operational oceanography constitutes a powerful tool to monitor, analyse and predict the state of marine resources as well as the sustainable development of coastal areas (Flemming et al., 2002).

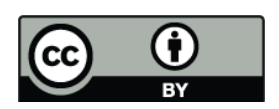

Correspondence to: A. Teruzzi (ateruzzi@ogs.trieste.it)
Improvement in short-term forecasts for the marine ecosystem to be employed within an environmental monitoring system is one of the main objectives pursued by the Global Monitoring for Environment and Security initiative (GMES; www.gmes.info). The Marine Environment and Security for the European Area (MERSEA) Strand-1 Project was launched in 2003 in order to assess European capabilities to enact the proposals of the marine GMES (Johannessen et al., 2006). This was then followed in 2004 by the MERSEA Integrated Project (MERSEA-IP; www.mersea. eu.org), whose primary objective was the deployment of a pan-European operational system for monitoring and forecasting ocean physics, biogeochemistry and ecosystem on a global and regional scale. The objectives of MERSEA-IP are scheduled to be further developed during the MyOcean initiative (www.myocean.eu.org), the implementation project of GMES Marine Core Service, which started in April 2009.

The TOPAZ system for the North Atlantic and Nordic Seas (topaz.nersc.no), operated by the Mohn-Sverdrup/Nansen Center, and the Medium Resolution Continental Shelf model for the north-west European continental shelf (http://www. ncof.co.uk/Ecosystems-Model-Forecast.html), managed by the UK National Centre for Ocean Forecasting, are examples of biogeochemical and ecosystem-level short-term prediction systems developed for some European regional seas.

An application of the operational monitoring and forecasting system expected within MERSEA-IP is particularly needed for the Mediterranean Sea, which is a naturally variable basin characterized by intense human pressure and is extremely vulnerable to environmental threats (Pinardi et al., 2006; Pinardi, 2007). This goal is pursued by the working group of operational and research institutes collaborating within the Mediterranean Operational Oceanography Network (MOON; www.moon-oceanforecasting.eu/), the coordinating body of EuroGOOS Mediterranean Task Team who

Published by Copernicus Publications on behalf of the European Geosciences Union. 
has developed the Mediterranean ocean Forecasting System (MFS; gnoo.bo.ingv.it/mfs; Pinardi et al., 2003) starting from the MFSTEP project (www.bo.ingv.it/mfstep). Although operational forecasting in the Mediterranean Sea has greatly improved during the last decade, biogeochemical applications have been less pursued compared to those related to the marine physical state (Pinardi et al., 2006). MOON aims at improving the capacity of operational modelling of the biogeochemical cycles in the Mediterranean Sea, both on a regional and basin scale.

As the marine ecosystem component of MFS, the coupled eco-hydrodynamic model OPATM-BFM (Océan PArallelisé Transport Model - Biogeochemical Flux Model), initially conceived to supply boundary conditions for the coastal biogeochemical models developed under MOON, has become one of the most promising results of MERSEA-IP. During this project, this model successfully delivered via web preoperational short-term hindcasts/forecasts of some key biogeochemical variables for the Mediterranean basin.

The integration of OPATM-BFM in a pre-operational setting specifically designed for the Mediterranean basin (a task carried out by OGS within MERSEA-IP and included in the MyOcean services catalogue) and the discussion of the results obtained by the system in the framework of the operational objectives required by MERSEA-IP and MyOcean projects, is the focus of this work. In particular, we illustrate in detail the preparation and implementation stages together with an evaluation of the first system entirely devoted to routinely providing short-term forecasts for Mediterranean Sea biogeochemistry. In view of the operational background of this work, model results are compared with data of chlorophyll concentration provided by remote sensing colour measurements for the period covered by the pre-operational system. Comparison with other variables and over a longer time period will be presented in major detail in another ad hoc contribution that discusses the OPATM-BFM model adopted for the pre-operational system (Lazzari et al., 2010).

The technological and scientific results obtained so far illustrate that the system worked properly during the testing phase, satisfactorily reproducing the features of the chlorophyll seasonal cycle in the Mediterranean basin during the period under study, as well as the dynamics of a localized chlorophyll bloom event. The interdisciplinary effort under OGS coordination in the framework of the Italian GNOO (Gruppo Nazionale di Oceanografia Operativa - National Group of Operational Oceanography; gnoo.bo.ingv.it/) enabled the development of all the components constituting the OPATM-BFM system.

The following section describes the model structure, Sect. 3 deals with the multi-disciplinary background infrastructure, Sect. 4 summarises the results obtained over one year of pre-operational activity with a final discussion of the on-going development of the system. The conclusions are drawn in Sect. 5.

\section{OPATM-BFM model overview}

OPATM-BFM is a transport-reaction model that numerically solves the time evolution of chemical and biological state variables in the marine environment. It is based on the coupling between the OPA Tracer Model version 8.1 (Madec et al., 1998) and the Biogeochemical Flux Model (BFM; Vichi et al., 2007a, b).

The governing equations are formulated as advectiondiffusion-reaction equations, one for each variable:

$$
\begin{aligned}
\frac{\partial c_{\mathrm{i}}}{\partial t} & =-\boldsymbol{U} \cdot \nabla c_{\mathrm{i}}+(-1)^{n+1} k_{\mathrm{h}} \nabla_{\mathrm{h}}^{2 n} c_{\mathrm{i}} \\
& +\frac{\partial}{\partial z}\left[k_{\mathrm{v}} \frac{\partial c_{\mathrm{i}}}{\partial z}\right]+w_{\mathrm{si}} \frac{\partial c_{\mathrm{i}}}{\partial z}+R_{\mathrm{bio}}\left(c_{\mathrm{i}}, c_{1} \ldots c_{\mathrm{N}}, T, I \ldots\right)
\end{aligned}
$$

where $c_{\mathrm{i}}=c_{\mathrm{i}}(\boldsymbol{x}, t)$ is the biogeochemical concentration of the $i$-th state variable, $-\boldsymbol{U} \cdot \nabla c_{\mathrm{i}}$ is the advection term $(\boldsymbol{U}$ is the velocity), $(-1)^{n+1} k_{\mathrm{h}} \nabla_{\mathrm{h}}^{2 n} c_{\mathrm{i}}$ is the horizontal diffusion term, with $k_{\mathrm{h}}$ the horizontal eddy diffusivity and $n=1,2$ according to, respectively, the Laplacian or bi-Laplacian scheme, and $\frac{\partial}{\partial z}\left[k_{\mathrm{v}} \frac{\partial c_{\mathrm{i}}}{\partial z}\right]$ the vertical diffusion, with $k_{\mathrm{v}}$ the vertical eddy diffusivity. The previous term allows simulation of vertical mixing, a fundamental environmental process for ecosystem evolution. The fourth term on the RHS represents the sinking process, and $w_{\mathrm{si}}$ is the particulate sinking velocity, while the last term $R_{\text {bio }}$ is the biological reactor ( $T$ is temperature, $I$ is irradiance). The initial and boundary conditions are:

$c_{\mathrm{i}}\left(x \in D, t=t_{0}\right)=c_{\mathrm{i}}^{0}$

$c_{\mathrm{i}}(x \in \partial D, t)=\mathrm{BC}(x \in \partial D, t)$

where $\partial D$ is the boundary of the model domain $D$ where the boundary conditions (BC) hold.

In this work, BFM implements the generic term $R_{\text {bio }}$. BFM is based on cycles of Carbon and macronutrients (Phosphorous, Nitrogen and Silica), and is targeted on the phytoplankton-nutrients dynamics and microbial loop. Key aspects of the BFM are its potential for limitation by macronutrients (Nitrogen, phosphate and silicate), the use of adjustable C:N:P:Si ratios in plankton compartments, and the chlorophyll to carbon variable ratio.

BFM was chosen as biogeochemical reactor since many complex processes/features present in this model are known to be relevant for the Mediterranean Sea:

- microbial loop (Thingstad and Rassoulzadegan, 1995);

- multi-nutrient description of biogeochemical cycles (Ribera d'Alcalà et al., 2003);

- presence of different phytoplankton functional types with no clear permanent prevalence of key species. 
In order to include all these features in the pre-operational forecasting system we chose to adopt BFM as a well-known, state-of-the-art model formulation. Moreover, BFM had already been successfully applied to several areas of the Mediterranean Sea (Allen et al., 2002; Vichi et al., 2003; Polimene et al., 2006; Petihakis et al., 2009).

The simulations are carried out by coupling OPATM-BFM with a high resolution Ocean General Circulation Model (OGCM). A description of the coupling between the OGCM and BFM follows.

\subsection{Biogeochemical-physical coupling and physical forcing}

The coupling allows the integration of (Eq. 1), provided the physical fields (i.e. velocity, temperature, salinity, irradiance, eddy diffusivity coefficient and wind speed) to the advection, diffusion and reaction terms. It is worth noting that the advection and diffusion terms are linear. Conversely, BFM depends non-linearly on temperature and irradiance.

Coupling may be implemented in two ways: on-line or off-line. In the on-line approach a synchronous solution of the OGCM equation and transport-reaction equation is carried out, thus meaning that the two models are running simultaneously. The on-line approach is the "standard" way of coupling (Crise et al., 1998). In the off-line approach the physical fields are considered as an external forcing hence they must already be computed before the integration of the transport-reaction equation. One of the hypotheses of the offline approach is that the generic biogeochemical concentration $c_{\mathrm{i}}$ does not influence the physical fields, therefore $c_{\mathrm{i}}$ is passively transported by the current. This hypothesis holds since, generally, the physical processes are mostly independent of the biology (Mann and Lazier, 1991).

The off-line approach was chosen for this application principally for the following reasons:

1. In off-line operational applications, any upgrade in the OGCM model (e.g. evolution of the data assimilation skill, advancements in the numerical scheme or in the parameterizations) is directly reflected in an improvement of the physical forcing for the biogeochemistry.

2. The BFM parameters have been estimated mainly through experiments defined by constant light and external conditions (Baretta-Bekker, 1995), and this approach is therefore consistent with daily mean forcings used in the present off-line coupling.

3. In highly complex models such as OPATM-BFM the off-line approach enables the computational burden to be reduced. Moreover, the integration time-steps for physics and biology are decoupled, therefore the biogeochemistry equations can be integrated using a larger time-step, dramatically improving performance.

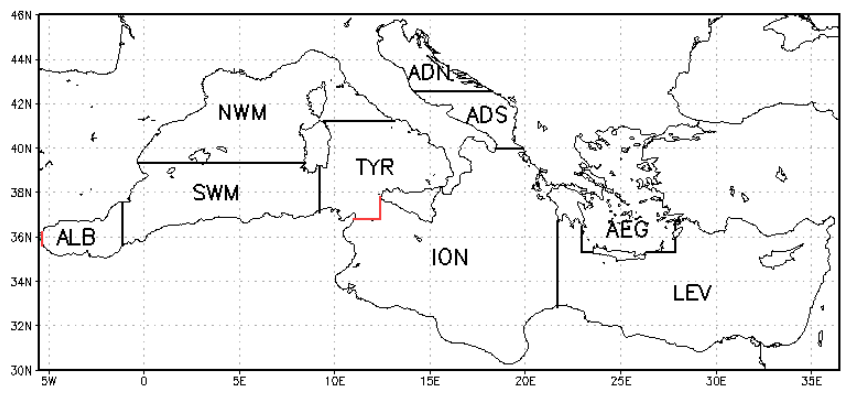

Fig. 1. Map of the Mediterranean Sea with selected subbasins of investigation: ALB = Alboran Sea, SWM = southwestern Mediterranean Sea, NWM = north-western Mediterranean Sea, TYR = Tyrrhenian Sea, ADN = northern Adriatic Sea, $\mathrm{ADS}=$ southern Adriatic Sea, $\mathrm{AEG}=$ Aegean Sea, ION = Ionian Sea, LEV = Levantine basin. Transects at the Gibraltar and Sicily Straits are depicted in red.

4. It is possible to implement new versions of the OPATMBFM code on different computational infrastructures using exactly the same stored physical forcings.

5. High frequency numerical noise, often introduced by data assimilation schemes, is filtered out by daily means.

In the pre-operational infrastructure which started during the MERSEA-IP project, the physical forcing fields were provided by the MFS-SYS2b ocean forecasting system managed by INGV (Istituto Nazionale di Geofisica e Vulcanologia, Bologna, Italy). This system is based on the OPA8.2 model (Madec et al., 1998) implemented on the Mediterranean Sea (Tonani et al., 2008) and includes as assimilation scheme the System for Ocean Forecasting and Analyses (SOFA; Dobricic et al., 2007). MFS-SYS2b has been intensively validated and today represents one of the most advanced tools for simulation of circulation in the Mediterranean Sea.

The INGV circulation model supplies three-dimensional and two-dimensional surface physical forcing fields for the Mediterranean Sea domain (Fig. 1): the first are zonal, meridional and vertical current speeds, vertical eddy diffusivity, temperature and salinity, the second are solar shortwave irradiance and wind speed. The three velocity components are necessary to calculate the transport term for each passive tracer. Eddy diffusivity is relevant to reproduce the vertical mixing processes of the tracers along the water column. Temperature, salinity, irradiance and wind speed enter as regulating terms in the biogeochemical reaction term $R_{\text {bio }}$ of (Eq. 1).

The horizontal resolution of OPATM-BFM is $1 / 8^{\circ}$ while that of the INGV model is $1 / 16^{\circ}$, therefore to reduce the finer grid to the coarser one an interpolating interface is necessary.

Interpolation is implemented by a mesh merging technique: the coarse grid is obtained by merging four adjacent cells of the finer grid (by a cell surface weighted average). 
Horizontal velocity fields are calculated with the constraint of preserving fluxes along the same vertical cross-sections:

$\int_{\mathrm{A}} \boldsymbol{u}_{\mathrm{h}}^{\mathrm{A}} \cdot \boldsymbol{n}^{\mathrm{A}} d A=\int_{\mathrm{B}} \boldsymbol{u}_{\mathrm{h}}^{\mathrm{B}} \cdot \boldsymbol{n}^{\mathrm{B}} d B$

where A and B are the discretization of the same vertical cross-section defined respectively on the INGV model grid and on the OPATM-BFM grid, $\boldsymbol{u}_{\mathrm{h}}^{\mathrm{A}}$ and $\boldsymbol{u}_{\mathrm{h}}^{\mathrm{B}}$ are the original horizontal velocity and the interpolated one, $\boldsymbol{n}^{\mathrm{A}}$ and $\boldsymbol{n}^{\mathrm{B}}$ are the vectors normal to the surfaces $A$ and $B$.

Interpolated vertical velocity fields $w$ are then derived integrating the horizontal divergence of the velocity field:

$w(z)=-\int_{\text {Bottom }}^{z} \operatorname{div}_{\mathrm{h}}\left(\boldsymbol{u}_{\mathrm{h}}^{\mathrm{B}}\right) d z$

The vertical resolution (72 z-levels, see also Sect. 2.4) is left unchanged in order to maintain a good reproduction of vertical dynamics and mixing of the water column, which is known to be of great relevance for biogeochemical processes (Mann and Lazier, 1991).

For what concerns time resolution, forcing data are stored as daily means, filtering out all the fast gravity waves which do not contribute substantially to the general circulation. The tracer model of the OPATM-BFM system, which has an integrating time step of $30 \mathrm{~min}$, computes the values of the forcing fields between each frame by a linear interpolation in time.

The skill of the spatial interpolation scheme was checked on the advective and diffusive processes. In Fig. 2 we show water mass inflow, outflow and net flow for the Gibraltar and Sicily Straits sections (see Fig. 1), evaluated on the period under study: the net horizontal fluxes of mass computed after the interpolation $\left(1 / 8^{\circ}\right)$ are equal to the original ones $\left(1 / 16^{\circ}\right)$ for the condition imposed in (Eq. 4). The slight differences between inflow and outflow fluxes are caused by the resolution-dependent sections used in the two estimates. These differences can be evaluated as around $1 \%$ of the inflow and outflow fluxes.

In Fig. 3 we show four monthly profiles of the vertical eddy diffusivity coefficient $\left(k_{\mathrm{V}}\right)$ spatially averaged over two sub-basins of the Mediterranean Sea, NWM and LEV (see Fig. 1). The interpolation acts on each level and the vertical profiles of $k_{\mathrm{V}}$ before and after the interpolation remain preserved throughout the period considered, with small discrepancies observed in May (around $100 \mathrm{~m}$ depth in NWM and around $40 \mathrm{~m}$ in LEV).

\subsection{BFM customisation}

The BFM was tailored to be more specifically suitable for our purposes: the formulation and the parameters of the BFM configuration used in this work are all provided in
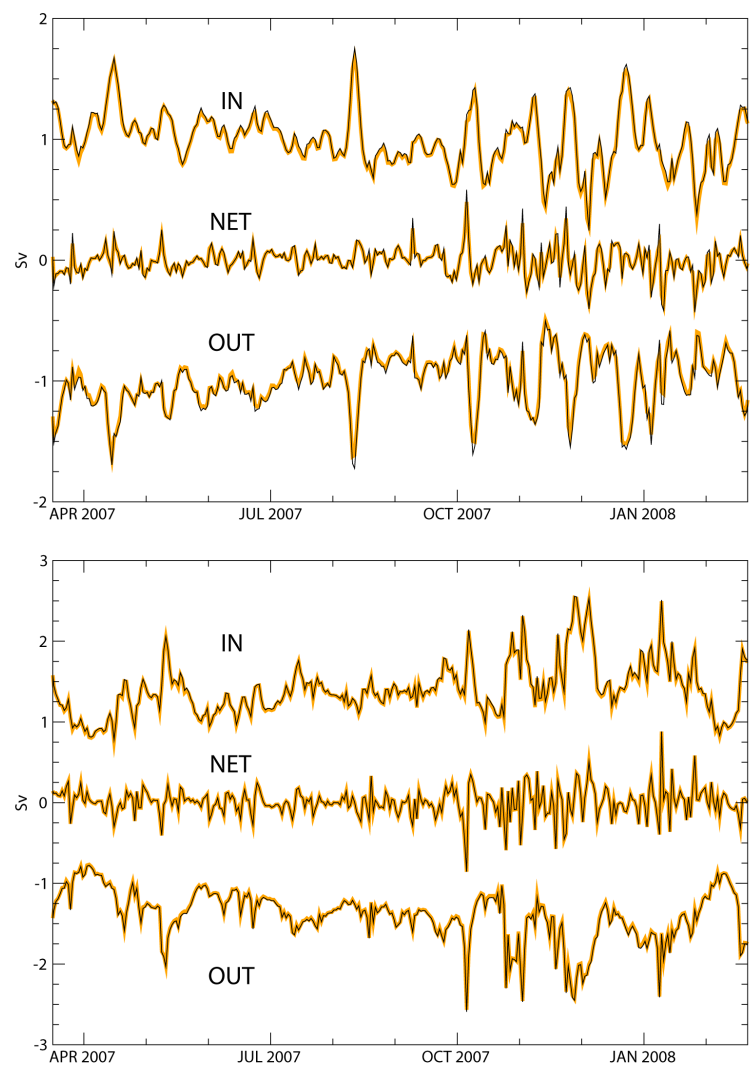

Fig. 2. Water mass inflow, outflow and net flow for the Gibraltar Strait section (top) and the Sicily Strait section (bottom) before (black) and after the interpolation (orange). The Straits sections are plotted in Fig. 1.

the supplementary material (http://www.ocean-sci.net/6/25/ 2010/os-6-25-2010-supplement.pdf). A summary of the main features of our BFM customisation follows.

Since the bottom fluxes effects are negligible for the relatively short time scale considered in the operational simulations, the benthic compartment of the model has been switched off as in other basin scale models of the Mediterranean Sea (Crise et al., 1998). Furthermore, no-flux boundary condition for the generic tracer holds at the bottom level.

Similarly to the BFM global Ocean PELAGOS version (Vichi et al., 2007a), in this implementation four types of living functional groups (phytoplankton, mesozooplankton, microzooplankton and bacteria) are included. The specific functional groups here considered are listed in the supplementary material (http://www.ocean-sci.net/6/25/ 2010/os-6-25-2010-supplement.pdf), which also provides their parameterisation.

In this implementation the number of prognostic variables is 51 , while the number of parameters is over 120 . For such a high number of degrees of freedom, a brute force approach to estimating sensitivity in a three-dimensional environment is not feasible. The model was initially calibrated by 
empirically testing the sensitivity of its implementation, confirming what had already been found in other models: the most sensitive parameterisation was that related to photosynthesis and respiration processes (Varela et al., 1995), with a significant role played by bacterial activity. The same tests showed the importance of light parameterisation: the light model here adopted is the Lambert-Beer non-spectral approximation that is commonly used for Mediterranean Case 1 water (e.g. Allen et al., 2002; Crise et. al., 1998).

The model parameters were tuned for the Mediterranean Sea in the framework of the MFSTEP project (see details in Lazzari and Crise, 2006). In this parameterisation the main differences compared to the PELAGOS global model (Vichi et al., 2007a) can be summarized as follows:

- no iron dynamic formulation; according to Guerzoni et al. (1999) iron is not a limiting nutrient in the Mediterranean Sea due to abundant atmospheric deposition originated by Saharan dust;

- dinoflagellates phytoplankton functional type is present according to the ERSEM implementation (BarettaBekker et al., 1997);

- the chlorophyll synthesis module is based on the Geider photo-acclimation model (Geider et al., 1997), without the parameterization described in Behrenfeld et al. (2004) and included in Vichi et al. (2007a).

\subsection{Initial and boundary conditions}

The time scales explored by the operational models are typically short and therefore deserve to have accurate sets of initial and boundary conditions. This procedure substantially reduces the spin-up time and facilitates convergence towards a realistic solution. Great care was taken in the collection and definition of the initial conditions for the described forecasting system.

The nutrient pools (Nitrogen, phosphate, silicate) and Oxygen for the biogeochemical model BFM were initialised with the vertical profiles provided by a retrospective reanalysis carried out during the MFSTEP project over the MEDARMEDATLAS 2002 data set (Crise et al., 2003). The data considered in this analysis concerned dissolved Oxygen (from 1948 to 2002), nitrate (from 1987 to 2002), phosphate (from 1987 to 2002) and silicates (from 1987 to 2002). A nutrient vertical profile was assigned to each of the eleven subdomains of the Mediterranean basin discussed in Crise et al. (2003). The other biogeochemical state variables were initialised homogeneously in the photic layer $(0-200 \mathrm{~m})$ following the standard BFM values, and with low values in the deeper layers. A smoothing algorithm was applied to manage the discontinuity between the different sub-domains.
The model presents two kinds of boundary conditions: at the Gibraltar Strait with the Atlantic buffer zone and in correspondence with riverine inputs. A seasonal nudging for phosphate, nitrate, silicate, dissolved Oxygen is forced at the Gibraltar Strait, consisting of a longitudinally dependent Newtonian relaxation term based on the climatological MEDAR-MEDATLAS fields. The time scales used in the nudging vary from 90 days (in proximity of the outer boundary) to 2 days (near the Gibraltar Strait). The riverine input takes into account the climatological nutrient load of three major Mediterranean rivers - Po (Palmeri et al., 2005), Rhone (Moutin and Raimbault, 2002), Nile (Nixon, 2003) together with the input from Dardanelles (Polat et al., 1997), accounting for $40 \%$ of the total land-based freshwater input. In addition, river plumes can detach from the coast and influence the open sea, thus reducing the filtering effect of coastal processes. The riverine loads are currently parametrized on a seasonal base similarly to the Atlantic box, using a climatological relaxation to the nutrient load quoted above with time scale equal to $1 \mathrm{~h}$.

\subsection{Numerical implementation}

The numerical time integration of (Eq. 1) is splitted in two phases, the first based on a first order forward time scheme, and the second by an implicit scheme:

$$
\begin{gathered}
c_{\mathrm{i}}^{*}=c_{\mathrm{i}}^{t}+\Delta t\left\{-\boldsymbol{U} \cdot \nabla c_{\mathrm{i}}^{t}+(-1)^{n+1} k_{\mathrm{h}} \nabla_{\mathrm{h}}^{2 n} c_{\mathrm{i}}^{t}\right. \\
\left.+w_{\mathrm{si}} \frac{\partial c_{\mathrm{i}}^{t}}{\partial z}+R_{\text {bio }}\left(c_{\mathrm{i}}^{t}, c_{1}^{t} \ldots c_{\mathrm{N}}^{t}, T, I \ldots\right)\right\} \\
c_{\mathrm{i}}^{t+1}=c_{\mathrm{i}}^{*}+\Delta t \frac{\partial}{\partial z}\left[k_{\mathrm{v}} \frac{\partial c_{\mathrm{i}}^{t+1}}{\partial z}\right]
\end{gathered}
$$

where the time step $\Delta t$ is $1800 \mathrm{~s}$.

In the first phase, advection, horizontal diffusion, sinking term and biogeochemical reactions are computed, while in the second phase only the vertical diffusivity is computed.

The Smolarkiewicz advection scheme (Smolarkiewicz, 1983 ) is adopted to reduce the intrinsic numerical diffusion of the advection scheme, and a bi-Laplacian horizontal diffusion $\left(k_{\mathrm{h}}=3 \times 10^{9} \mathrm{~m}^{4} \mathrm{~s}^{-1}\right.$ constant in space and time, $n=2$ in Eq. 6) was chosen to preserve the sharpness of the propagation fronts associated to the biogeochemical concentrations. Further details are reported in Lazzari et al. (2005).

The geographical domain covered is the Mediterranean Sea and part of the Atlantic Ocean, from $8.78125^{\circ} \mathrm{W}$ to $36.3438^{\circ} \mathrm{E}$ and from $30.2188^{\circ} \mathrm{N}$ to $46.0938^{\circ} \mathrm{N}$, with a uniform horizontal resolution of $1 / 8^{\circ}$ and 72 vertical z-levels (18 levels from surface to $100 \mathrm{~m}$ depth, 7 between 100 and $200 \mathrm{~m}$ depth, 12 between 200 and $500 \mathrm{~m}$ depth, 9 between 500 and $1000 \mathrm{~m}$ depth, 10 between 1000 and $2000 \mathrm{~m}$ depth and 16 below $2000 \mathrm{~m}$ ). The output data are released as daily means. 


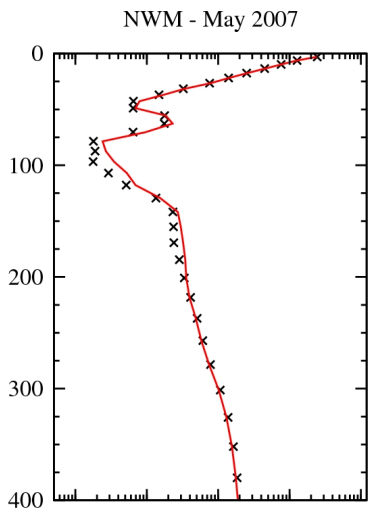

EME - May 2007

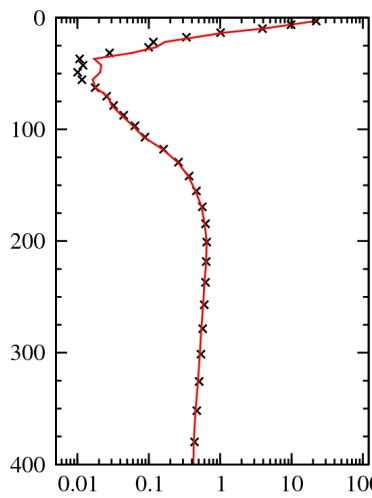

NWM - Aug 2007

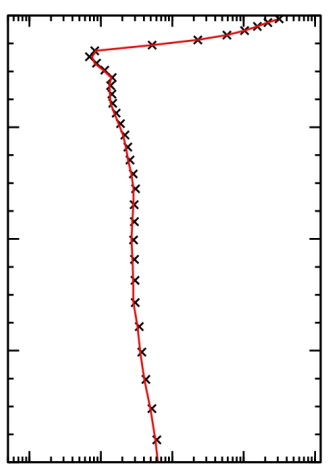

EME - Aug 2007

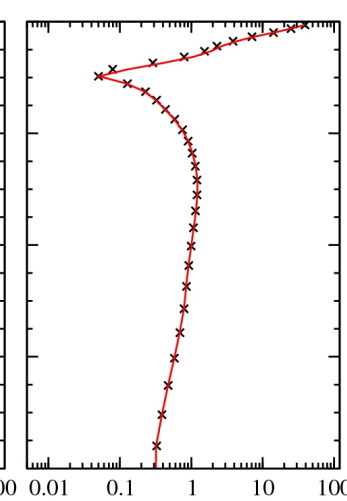

NWM - Nov 2007

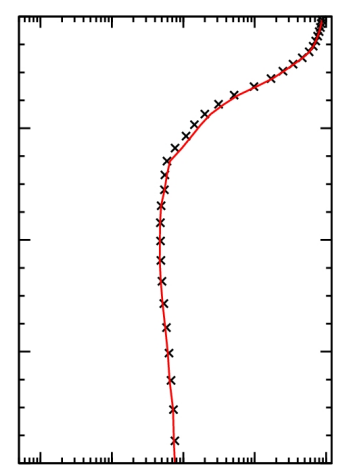

EME - Nov 2007

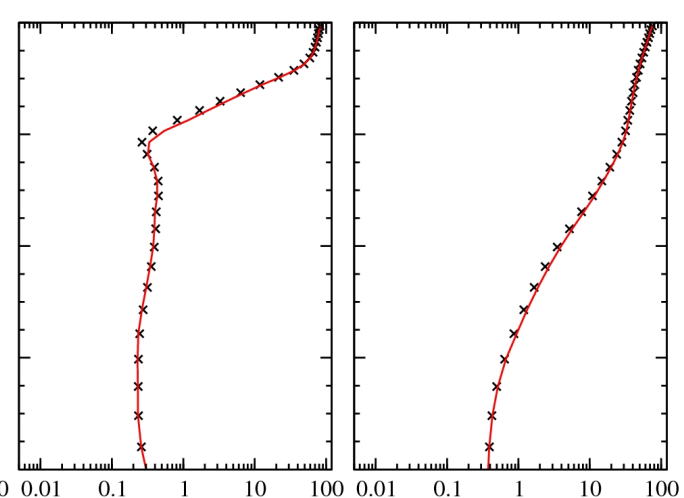

Fig. 3. Mean monthly vertical profiles of vertical eddy diffusivity coefficient $k_{\mathrm{V}}\left(\mathrm{m}^{2} / \mathrm{s}\right)$, areal-averaged over sub-basins NWM and LEV for the fine grid $\left(1 / 16^{\circ}\right.$; crosses $)$ and for the coarse grid $\left(1 / 8^{\circ}\right.$; red line $)$.

The three-dimensional computational domain resolved by the OPATM-BFM system has more than $3 \times 10^{6}$ cells and each run produces almost $2.7 \mathrm{~Gb}$ of data per day of integration. In particular, the weekly run launched for the operational forecasting system (see the following section for details) produces more than $113 \mathrm{~Gb}$ of data.

The OPATM-BFM code was parallelized by means of the message passing paradigm (using the MPI library) through the domain decomposition approach. This method consists in splitting the computational domain in smaller sub-domains: each processor works exclusively on one of the sub-domains assigned at initialisation, exchanging the necessary cells only with its neighbours. The default algorithm for the splitting of the horizontal domain is a simple, automatic, static decomposition that subdivides the domain in regular sub-domains. When this type of two-dimensional partitioning is applied to an irregular domain such as the Mediterranean basin, it produces a computational load imbalance among processors due to the very different number of sea grid points that every processor has to compute. To reduce the imbalance related to the default decomposition, we introduced allocatable memory in the structure of the code and a pre-processing procedure that computes the best domain decomposition through an iterative algorithm that distributes the computational cells equally among processors. This adaptive domain decompo- sition maintains the load balance efficiency to an acceptable $80 \%$ even when the number of processors is increased from 32 to 64 , a configuration that in the default algorithm accounts for a load balance efficiency lower than $10 \%$.

The production runs reported in this paper were executed using 32 processors of the IBM-sp5 facility hosted at CINECA (Bologna, Italy), with a memory request of $1.5 \mathrm{~Gb}$ for each processor. The weekly run that performs a total of 17 days of simulations is configured with a total of 816 time steps.

\section{The pre-operational system}

The OPATM-BFM coupled eco-hydrodynamic model is the core of the pre-operational procedure embedded in the OGS operational system, which aims at producing analyses and forecasts of the Mediterranean Sea biogeochemistry on a weekly basis.

The products of the simulations are the concentrations of key variables (macronutrients, chlorophyll) and are routinely delivered from the OGS website (http://poseidon.ogs. trieste.it/cgi-bin/opaopech/mersea) in order to track the temporal and vertical evolution of the basin's biogeochemical properties. Surface maps and vertical sections have been 
made available as of 1st April 2007 (beginning of TOP2, Toward Operational Phase 2), during the MERSEA-IP development. Chlorophyll concentration is the service product of the OPATM-BFM system requested by the zero-version of the MyOcean catalogue.

The pre-operational system (also referred to as preoperational chain) is a multidisciplinary effort that involves four different Italian scientific institutes:

- OGS, which manages the OPATM-BFM model and is responsible for the correct functioning of the whole system;

- INGV, which provides the physical forcing fields needed to drive the biogeochemical model as outputs from the MFS-Sys2b OGCM model;

- CINECA, which hosts the computational facility where the whole system runs weekly fully automatic and unattended (an external intervention from OGS or CINECA staff is necessary only in case of failure due to a breakdown in communication between the INGV server - where the physical forcing fields are stored - and CINECA server - where OPATM-BFM runs - or due to technical problems at CINECA);

- ISAC-CNR, which provides the MODIS satellite images necessary for the comparison with the model results (at present, this institute is not actively involved in the pre-operational forecasting system but a quality control of the chlorophyll surface maps with satellite images is under study and will be included in the full operational development expected within MyOcean).

INGV and ISAC-CNR make the data available on their own ftp sites and OGS disseminates the products on its web site. These activities are in principle not synchronized, as they are carried out independently in geographically remote sites.

The collating element that sets the proper timing and synchronization of information flows is the operational chain. The operational chain is basically organized as a collection of programs and files implementing the following main functionalities:

- coordinating the input, production and dissemination stages necessary for the execution of OPATM-BFM that are described below;

- monitoring the status of the execution;

- obtaining diagnostics about any previously executed run, through the log files in order to investigate possible causes of failure;

- minimizing human intervention after system failures.

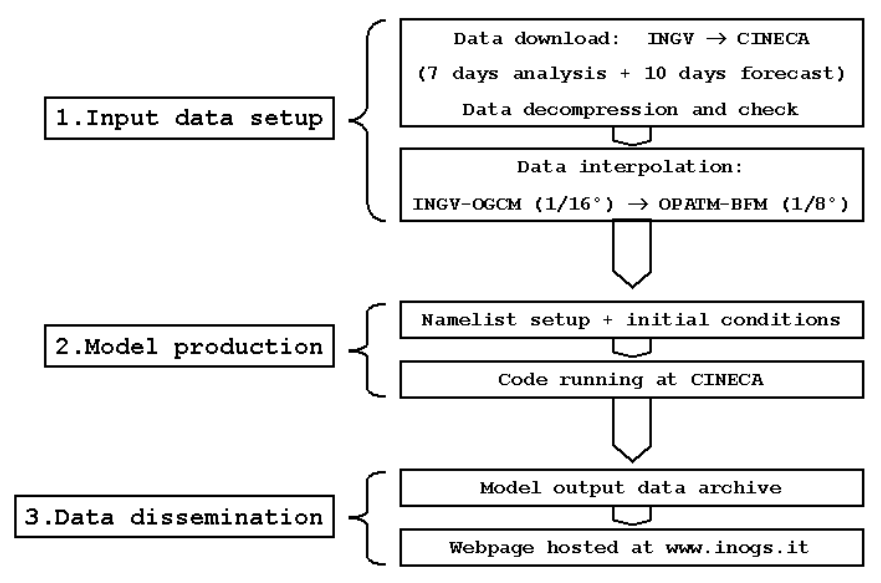

Fig. 4. Flow diagram of the pre-operational infrastructure system.

The operational chain creates a job command file for each run, which is submitted to the available scheduler. Most of these tools are implemented as Korn shell scripts. The operational chain also contains the sources of the model, all the Unix commands needed for execution and the OPATM-BFM configuration files. Moreover, the operational chain defines a directory structure for the log files, model execution and data archiving. All the files necessary in order to operate are managed through a versioning system, which permits full control of any development of the system components.

A specific protocol was defined to preserve the correct version of the whole chain and consequently the integrity of the model simulations, in order to make every run completely reproducible. Indeed, it is possible to restore the same release of the chain that was in production in any time in the past, and thus reproduce any run exactly.

The chain is composed of three main sequentially dependent steps (Fig. 4) that implement the three stages of the run that are described below.

\subsection{Setting up the physical forcing}

This stage includes the download of the input data from the INGV server to the CINECA server and the horizontal interpolation of the physical forcing fields (velocity, temperature, salinity, eddy diffusivity coefficient, irradiance and wind speed) from the $1 / 16^{\circ}$ grid of the OGCM model to the $1 / 8^{\circ}$ grid of the OPATM-BFM. The OGCM outputs are organized in 7 days of analysis starting from Tuesday of the previous week (day A1) to Monday of the current week (day A7) and 10 days of forecast starting from Tuesday of the current week (days F1, F2, ... F10), with a total of 17 daily fields (Fig. 5). The computational time needed to complete this stage is presently about $30 \mathrm{~min}$. 


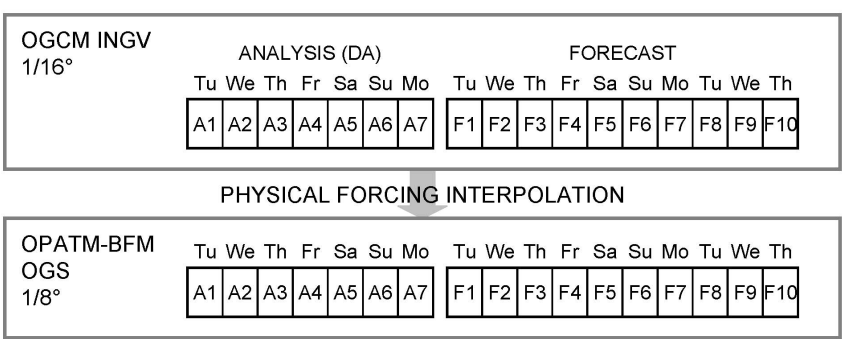

Fig. 5. Layout of the interpolation phase with reference to the weekly run; DA means "Data Assimilation" to indicate that the OGCM analyses are produced with the SOFA scheme.

\subsection{OPATM-BFM production}

This stage first sets the initial conditions and the ancillary files necessary for the code running, and then executes the OPATM-BFM production. The model is initialised in its biogeochemical state variables with the output fields relative to day A7 of the previous run (Fig. 5). The ancillary ("namelist") files set the parameters necessary for the model running (domain decomposition, time step, horizontal diffusivity coefficient, etc.). The results of this stage are 7 days of analysis, where the 7th day corresponds to Monday of the current week, and 10 days of forecast (Fig. 5). The computational time needed for the model execution in the current configuration is about $4.5 \mathrm{~h}$ on 32 processors of the IBM-sp5.

The OPATM-BFM code is purely prognostic: no assimilation scheme has been implemented so far. The absence of such a scheme implies that the OPATM-BFM analyses are the result of INGV assimilated forcing only, without any type of assimilation of biogeochemical fields.

\subsection{Data dissemination}

The last stage includes the post-processing applications that generate the graphic plots and the ftp transfer of the maps from CINECA to OGS server. When this step is completed (currently in the order of one hour), the output fields become available on the OGS web page and are organized in:

1. surface maps of chlorophyll, phosphate, nitrate, ammonia, silicate (produced by the OPATM-BFM model), temperature and salinity provided by the INGV model for 7 days of analysis and 10 days of forecast;

2. temporal evolution along the whole run ( 17 days) of the vertical profiles of chlorophyll and phosphate and of temperature and salinity for selected sub-basins of the Mediterranean Sea;

3. mean vertical cross-sections (for 7 days of analysis and 7 days of forecast) of chlorophyll and phosphate along: $5.5^{\circ} \mathrm{E}, 19^{\circ} \mathrm{E}, 28^{\circ} \mathrm{E}, 35^{\circ} \mathrm{N}$, and $40^{\circ} \mathrm{N}$.
This step also includes data archiving, which consists of the storage of the model outputs and of all the files needed for an eventual re-run of the simulation (restart files and physical forcing fields). These files are compressed and stored at CINECA, with an amount of memory for each weekly run of about $5 \mathrm{~Gb}$.

\section{Results and discussion}

The OPATM-BFM system achieved two types of results: technological and scientific. The technological results regard the implementation and successful functioning of the OPATM-BFM system. The scientific results are related to the comparison of the model outcomes with observations (see Sect. 4.1).

Since April 2007, the pre-operational infrastructure has offered short-term forecasts of meaningful biogeochemical variables in the Mediterranean basin (chlorophyll, nutrients) on a weekly basis. As of July 2007 the whole infrastructure has been fully automated. This achievement was demonstrated by continuous updating of the web page hosted by the OGS server, featured by more than 3000 visits and 17000 page views since September 2007. The deployment of a pre-operational forecasting system for Mediterranean biogeochemistry based on multiple platform, eco-hydrodynamic off-line coupling, one of the objectives of MERSEA-IP, has been completed successfully.

Considering the period from August 2007 to April 2009, 93 weekly runs were executed by the operational chain. In $87 \%$ of the runs the procedure effectively started automatically at noon of each Wednesday, for the remaining $13 \%$ of the runs it was necessary to operate manually in order to solve some issues of different nature (technical problems on the High Performance Computing cluster or internet connection failures) and re-submit the procedure.

The procedure usually takes less than $24 \mathrm{~h}$ to be fully completed $(72 \%$ of the runs, with an average length of $11.5 \mathrm{~h}$ ). The threshold of $24 \mathrm{~h}$ was exceeded in the remaining $28 \%$ of the runs, either due to the above mentioned technical problems or due to queuing for resources to become available. In particular, the longest waiting times are mostly related to the OPATM-BFM production which is the most computationally demanding phase.

\subsection{Analysis of surface chlorophyll results}

The OPATM-BFM system has demonstrated it can provide reliable information on Mediterranean Sea biogeochemistry in the period of analysis, supplying well-founded products for operational oceanography. Validation of the BFM model for the Mediterranean Sea is beyond the scope of this paper, and the results of the OPATM-BFM system are compared with data typically available in the operational context. The 
OPATM-BFM results were checked by analysing and comparing them with remote satellite data provided by ISACCNR, which have a spatial and temporal coverage similar to the basin-scale model results. In particular, results analysis concerns surface chlorophyll, evaluated as chlorophyll concentrations averaged over the first optical length. The focus on chlorophyll concentration is also justified since this variable constitutes the service product of the zero-version of the MyOcean catalogue, as mentioned above. Since we assume no specific statistical distribution for surface chlorophyll, we use in the comparison non-parametric indicators such as median, 25th, 75th percentile area, minimum and maximum values, all of them evaluated over the whole Mediterranean basin or over selected sub-basins.

As described above, the OPATM-BFM daily fields (both forecasts and analyses) are available as of April 2007. For the following analyses we consider the period from April 2007 to September 2008, since post-processed satellite data are available for this time interval.

\subsubsection{Comparison between forecast and analysis}

Initially, we evaluated the difference between surface chlorophyll results forced by prognostic physical fields $\mathrm{F} n(n=$ 1,7; see Fig. 5) and those from assimilated physical fields A $n(n=1,7)$. In this case the investigation is extended to December 2008.

In Fig. 6 we show for each day of the period under evaluation the data relative to $\mathrm{F} 1, \mathrm{~F} 2, \ldots, \mathrm{F} 7$ and those corresponding to $\mathrm{A} 1, \mathrm{~A} 2, \ldots, \mathrm{A} 7$ that cover the same 7 days (see Fig. 5). Throughout the simulation period the ForecastAnalysis Difference (FAD, computed for every week as F $n$ A $n$ with $n=1,7$ ) shows no evident discrepancies. The average relative FAD for the median, the 25th and the 75th percentile are equal to $0.8 \%, 1.2 \%$ and $1.6 \%$, respectively. The significant agreement observable both for the median and for the two percentiles (Fig. 6) highlights a similar overall distribution. This remains almost constant throughout the simulation period, evidence that the FAD is clearly not timedependent. Accordingly, given the very small FAD observed for the OPATM-BFM, the following analysis on the model results will be made using the data relative to analyses (A1 ...A7) of each weekly run.

\subsubsection{Comparison between model and satellite data on the Mediterranean basin}

The model results were compared with remote sensing chlorophyll values measured by MODIS-Aqua satellite sensor (Fig. 7). The satellite and model data illustrated in Fig. 7 were geometrically averaged over a 5 day interval.

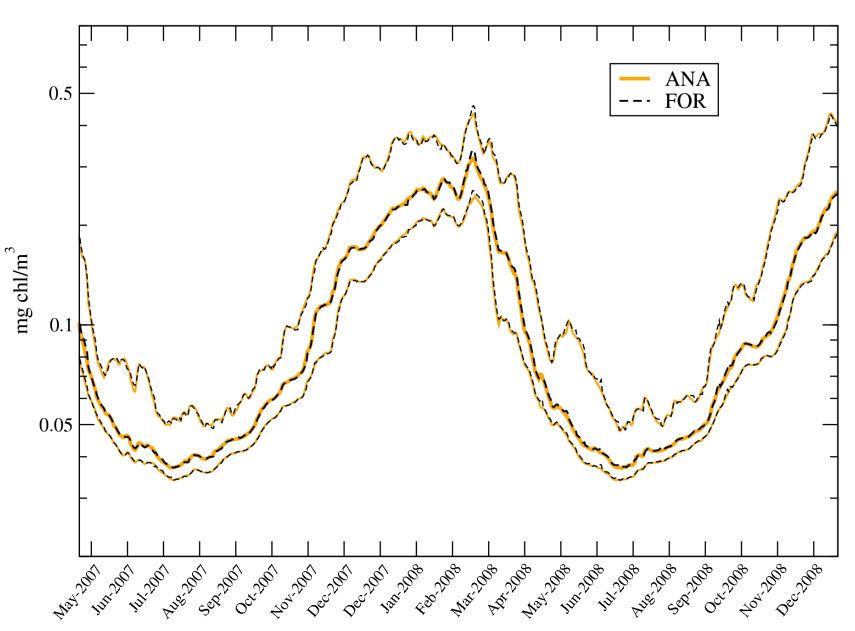

Fig. 6. Temporal evolution of the daily surface chlorophyll concentration spatially estimated over the Mediterranean Sea, obtained using the forecast (black dashed line) and the analysis (orange solid line): median (thick line), 25th and 75th percentile (thin lines).

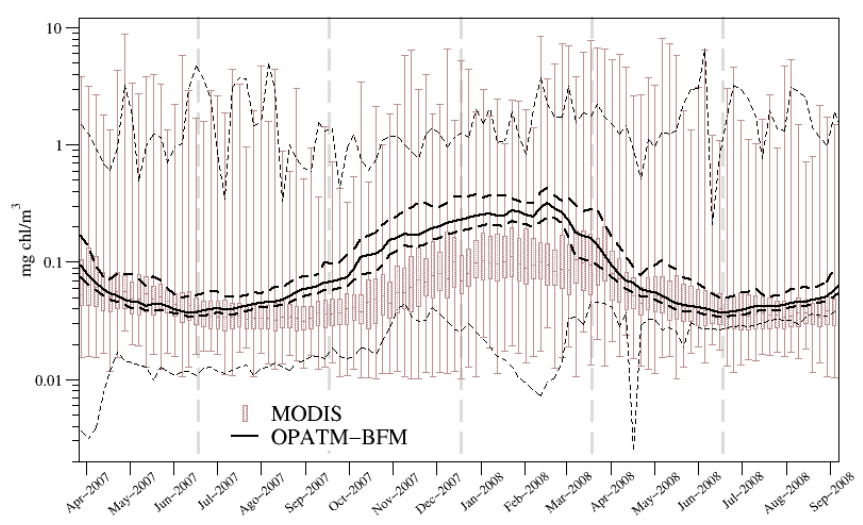

Fig. 7. Temporal evolution of the 5-day mean surface chlorophyll concentration for the Mediterranean Sea: biogeochemical model results (median, solid line; 25th and 75th percentiles, thick dashed line; minima and maxima, thin dashed line) and MODIS satellite data (box and whisker plot). Seasons as discussed in Fig. 10 are highlighted by the dashed grey lines.

MODIS-Aqua data were processed by the Satellite Oceanography Group of the Rome Institute of Atmospheric Sciences and Climate - CNR (GOS-ISAC-CNR). Level-0 data were acquired via ftp from the Goddard Space Flight Center (NASA) at full resolution $(1 \mathrm{~km})$ and processed up to Level-3 with the SeaWiFS Data Analysis System (SeaDAS) software package version 5.1.5 available from NASA website (seadas.gsfc.nasa.gov). Standard flags and Siegel's atmospheric correction algorithm were applied to Level-1A raw data. Chlorophyll concentrations were computed from Level-2 water leaving radiances, using a validated regional algorithm called MedOC 3 that takes into account the particular characteristics of the Mediterranean Sea (Santoleri et al., 2008). 
The temporal evolution of the median of surface chlorophyll concentration simulated by OPATM-BFM presents characteristics similar to those provided by the remote sensing measurements. As shown in Fig. 7 the satellite measurements are characterized by the typical mid-latitudes seasonal cycle (Longhurst, 2001; Bosc et al., 2004) with lower Summer values (July-August 2007 and 2008), a growth between October and November 2007, and a Winter plateau with higher values (January-March 2008). The model is able to reproduce the seasonal cycle with lower Summer values (June-July 2007 and 2008) a growth in August 2007 and higher Winter values (February-March 2008), thus showing a time lag in the seasonal chlorophyll cycle. During the Summer period the model median and variability are in good agreement with MODIS data, while from August 2007 to April 2008 OPATM-BFM overestimates the satellite data. The overall agreement between the temporal evolution of the data and model median can be evaluated by means of Spearman correlation coefficient $\left(R_{\mathrm{S}}\right)$, which is equal to 0.71 .

The MODIS maximum estimates of surface chlorophyll concentration over the whole basin generally range 1$10 \mathrm{mg} \mathrm{chl} / \mathrm{m}^{3}$, the same holds for the model results.

As the surface variability of the chlorophyll signal over the whole basin is quite heterogeneous, we selected two subbasins, characterized by opposite regimes: north-western Mediterranean and Levantine basin (respectively NWM and LEV in Fig. 1). NWM is a mesotrophic sub-basin influenced by the Rhone outflow on the coastal area and subjected to vigorous convection during late Winter, while LEV is an oligotrophic sub-basin that exhibits a quasi-tropical regime with semi-permanent stratification and chronic shortage of nutrients in the euphotic zone (Figs. 8 and 9).

As observed for the entire Mediterranean basin, also the two selected sub-basins well reproduce surface chlorophyll concentrations during the Summer periods. During the September-February semester NWM shows an agreement with satellite estimations better than LEV, where the model highly overestimates MODIS data.

The model variability (25th-75th area) remains almost constant throughout the simulation for both the sub-basins whilst the satellite estimations show an increase in variability during Spring, especially in NWM where it is related to Spring bloom events. The $R_{\mathrm{S}}$ for chlorophyll median is equal to 0.71 and 0.70 for NWM and LEV, respectively.

Both maximum and minimum model values are satisfactorily in agreement with the respective satellite data in the two sub-basins.

The time-lag between the data and model above observed for the Mediterranean basin is also a common feature of the two selected sub-basins. The East-West chlorophyll gradient of the Mediterranean basin observed by many authors (e.g. Longhurst, 2001) is reproduced by OPATM-BFM, since in the period considered surface chlorophyll in NWM are mostly higher than the values simulated in LEV. This result confirms the validity of the BFM generic formulation, able to

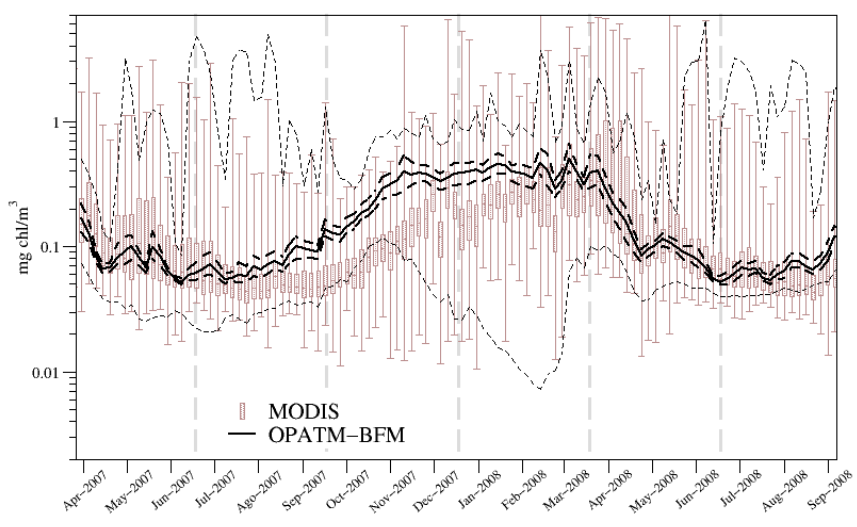

Fig. 8. Temporal evolution of the 5-day mean surface chlorophyll concentration for the NWM sub-basin: biogeochemical model results (median, solid line; 25th and 75th percentiles, thick dashed line; minima and maxima, thin dashed line) and MODIS satellite data (box and whisker plot). Seasons as discussed in Fig. 10 are highlighted by the dashed grey lines.

self-adjust to quite different environmental conditions without any specific parameterization.

Figure 10 shows a graphic representation of model skill compared to satellite observations by means of target diagrams (Jolliff et al., 2009), where each point is representative of a model grid cell. The target diagrams have been calculated for the four different seasons. The horizontal axis of the target diagram (TD) is based on the normalized unbiased root mean square difference (RMSD*'), which is an indicator of the agreement between the amplitude and phase of the temporal patterns of the model results and of satellite observations. The vertical axis is the normalized bias $\mathrm{B}^{*}$, which is proportional to the distance between the model and satellite mean. Furthermore, in the TD the distance from the origin represents the normalized root mean square difference (RMSD*), which is a measure of the average magnitude of the difference between model and satellite. The distance from the origin is basically an indicator of model skill, which improves as the diagram points go toward the origin. For details on the formulation of the statistics used in the TD, please refer to Appendix A and to Jolliff et al. (2009).

Looking at the general behaviour over the entire Mediterranean Sea, the diagrams of Fig. 10 allow us to make some observations on model skill:

- in Spring model skill is better than in the other seasons;

- both the Autumn and the Winter diagrams show an evident positive $\mathrm{B}^{*}$, indicating that the model generally overestimates the satellite values;

- in the Winter and Summer diagrams the RMSD*' has higher values than in the other two seasons, revealing that the temporal pattern is not captured by the model as well as in Autumn and Spring. 


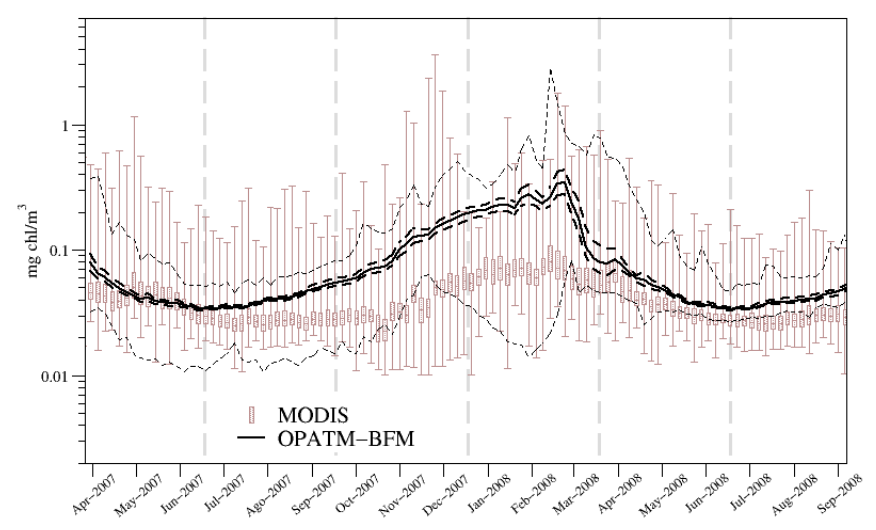

Fig. 9. Temporal evolution of the 5-day mean surface chlorophyll concentration for the LEV sub-basin: biogeochemical model results (median, solid line; 25th and 75th percentiles, thick dashed line; minima and maxima, thin dashed line) and MODIS satellite data (box and whisker plot). Seasons as discussed in Fig. 10 are highlighted by the dashed grey lines.

The issues arising from the TD can be related to the characteristics of Fig. 7. The positive $\mathrm{B}^{*}$ observed in the TD may be related to the overestimation of surface chlorophyll shown in Fig. 7, particularly during Autumn and Winter. Moreover, in Fig. 7 the model and satellite percentiles show a good agreement during Spring 2008, consistent with the good score of the model for this period in the TD. Finally, the higher values of RMSD*' for Summer and Winter diagrams may be related to the temporal lag observed in Fig. 7. Conversely, the Autumn and Spring diagrams are not affected by the temporal lag, as these seasons are characterized, both for the model and the satellite, by a persistent increasing/decreasing trend.

In the diagrams of Fig. 10 it is also possible to highlight some sub-basins specific features. In particular, we can focus on the two sub-basins examined in Figs. 8 and 9, i.e. NWM and LEV. The target diagrams show that the NWM is characterized by a better skill than the LEV, as can be also seen in Figs. 8 and 9. Besides this general observation, it is noteworthy that in the Summer diagram some points of the NWM have similar skill to those of the LEV (RMSD* between 9 and 12). This low score for the NWM may be related to the bias observable in Fig. 8 in the final part of the Summer 2007 period.

As indicated in Appendix A the sign on the horizontal axis of the TD is made by the difference between $\sigma_{m}$ and $\sigma_{r}$. Thus, when RMSD* ${ }^{*^{\prime}}$ is positive the $\sigma_{m}$ is greater than $\sigma_{r}$ and vice versa. The evaluation of the number of points with positive/negative RMSD*' ${ }^{\prime}$ indicates that for LEV most, or at least half, of the points have positive RMSD* ${ }^{\prime}$ for all the seasons, whilst for the NWM most of the points have negative RMSD*' in all the seasons except Summer. Referring to Figs. 8 and 9, the preponderance of positive RMSD*' for LEV is probably related to a higher range of temporal vari- ability of the model compared to the satellite, while a similar issue can not be observed for the NWM except for the Summer period.

Despite some model drawbacks arising from the previous analysis based on large scale averages, the OPATMBFM model is a powerful instrument to produce forecasts of Mediterranean biogeochemistry. Indeed, the model demonstrated its ability to correctly reproduce relevant localised events, whose dynamics cannot be captured by spatially and temporally filtered data processing as that adopted for example in Figs. 7-10 or by climatological averaging.

Figure 11 presents the surface chlorophyll concentration maps for some selected days between February and March 2009 in the Gulf of Lions. As shown by the satellite images (Fig. 11, top), the mixing in the centre of the Lions Gyre (probably ascribed to deep convection) is already present at the end of February and characterized by a surface chlorophyll concentration with values lower than $0.1 \mathrm{mg} / \mathrm{m}^{3}$. This minimum still appears evident on 12 March, when increasing chlorophyll concentration is observed in the southwestern area of the image. Between 15 and 17 March a bloom event develops, clearly visible in surface patches with chlorophyll concentration higher than $3 \mathrm{mg} / \mathrm{m}^{3}$, which expand and cover the area characterized by the lowest values. On 26 March the event is generally over.

The OPATM-BFM model demonstrates good performance levels by satisfactorily forecasting the temporal dynamics, the location and the intensity of the event (Fig. 11, centre). The qualitative comparison between the two sets of images confirms that the model is potentially capable of providing forecasts of local chlorophyll bloom events in the Mediterranean Sea, the only evident discrepancy being a bloom on 17 March that is slightly shifted south-westward with respect to the correspondent satellite image. Furthermore, the slight difference between the forecast (Fig. 11, centre) and the analysis (Fig. 11, bottom) confirms what has already been discussed in Sect. 4.1.1 relative to the surface chlorophyll statistics evaluated on the Mediterranean basin.

Bloom events in NWM are well known and their dynamics is recurrently reproduced by the model, mainly because this signal is very energetic and has a strong time dependency on physical forcing. Conversely, the intensity of blooms is directly dependent on nutrient supply, which can be quantitatively demonstrated to be hyperbolically dependent on the mixing depth. This non-linear response reduces the impact of the uncertainty of the mixing depth on vertical nutrient fluxes and consequently on bloom intensity. 

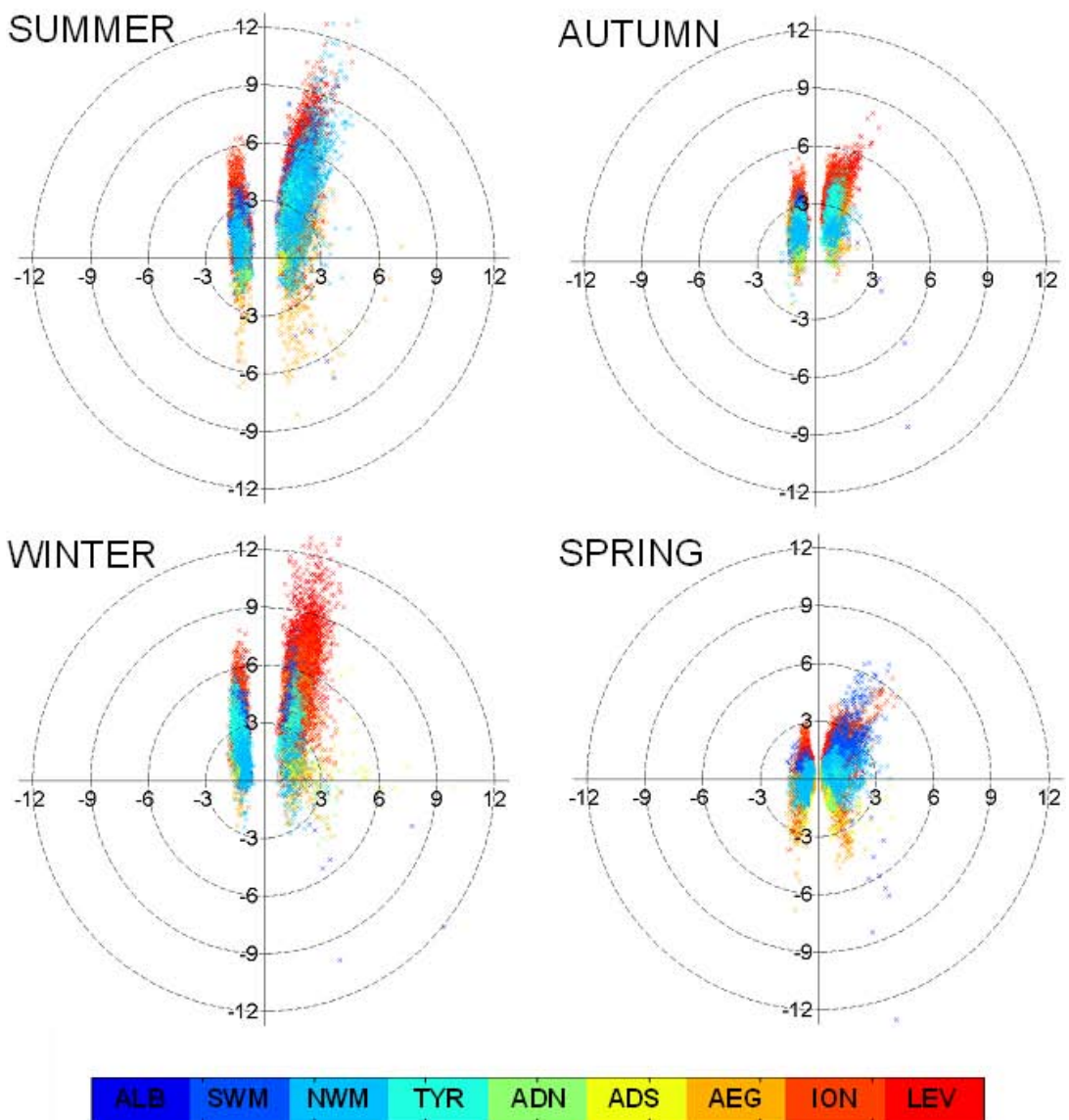

Fig. 10. Target diagrams for the four seasons: July-September 2007 (top, left); October-December 2007 (top, right); January-March 2008 (bottom, left) and April-June 2008 (bottom, right). Colours are relative to sub-basins under investigation.

\section{Conclusions}

A pre-operational, unattended and fully automatic procedure that provides public short-term forecasts of the Mediterranean biogeochemistry on a weekly basis has been developed in the framework of the MERSEA-IP project. This can be considered as the first example of such a system applied to the Mediterranean Sea.

The implementation has been coordinated by OGS with the cooperation of INGV and ISAC-CNR. The need for a sustained and truly operational approach for the forecasts led to the involvement of CINECA, the largest supercomputing centre in Italy, as the technical partner and computer services supplier.

Maps of biogeochemical key variables (e.g. chlorophyll and nutrients) have been disseminated via web since April 2007. The results obtained so far can be considered from the technological and scientific point of view.

Firstly, the fully automatic and unattended execution of the whole pre-operational procedure (job submission, model production, archive and dissemination on the website) started and correctly concluded in $87 \%$ of the runs, with an average duration of $16 \mathrm{~h}$ from job submission. This result is particu- larly satisfactory since no dedicated resources and/or specific priority has been given to the operational chain. Moreover, as can be observed in Fig. 6, it was never necessary to reinitialise the system, thus implying a continuity and a consistency in the products time series.

Secondly, two different models (the OPA Tracer Model and the BFM) were successfully coupled to give rise to the OPATM-BFM code, which has been built up through an intensive parallel optimisation of the OPATM-BFM transport model. The off-line strategy chosen to couple physics and biogeochemistry was very useful since it makes possible to use different OGCMs to force the biogeochemical model. This means that every improvement in the physical model is directly reflected in the biogeochemical compartment. In perspective, backup physical forcings may be used in case of missing INGV data, ensuring higher system reliability.

Considering the scientific point of view, the preoperational system represents an assemblage of codes (i.e. the OPA, MFS and BFM models) that were previously verified only individually. The analysis of these results has hence allowed an assessment of the system as a whole, exploiting previous scientific achievements obtained by each component and applied to the Mediterranean Sea. 

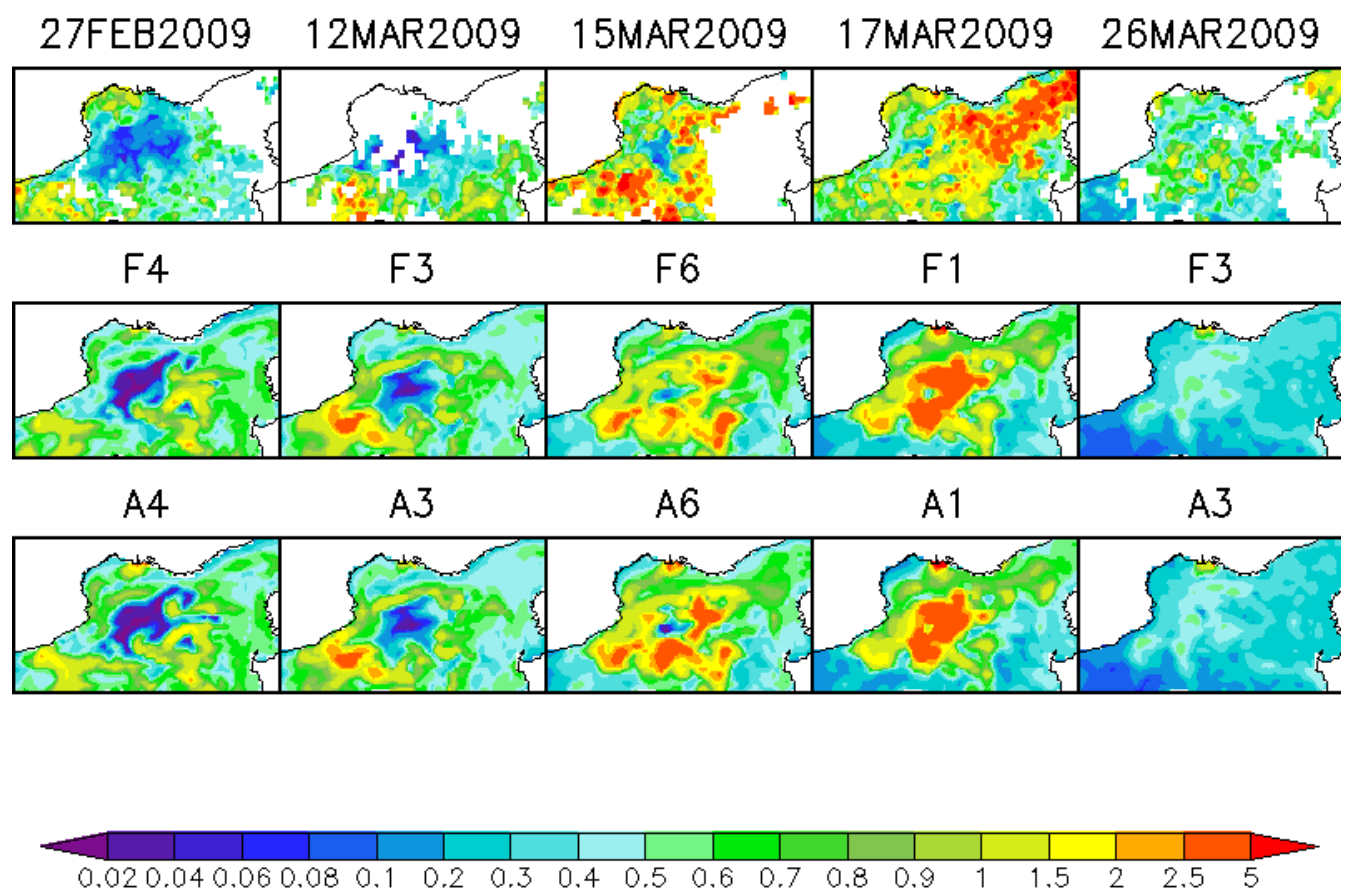

Fig. 11. Surface chlorophyll concentration $\left(\mathrm{mg} \mathrm{chl} / \mathrm{m}^{3}\right)$ observed between February and March 2009 in the Gulf of Lions: MODIS-Aqua satellite (top), OPATM-BFM model forecasts (centre) and analyses (bottom). The labels F\# and A\# refer to Fig. 5.

We analysed the system performance from an operational point of view, comparing the model results with observations available for the period considered with a spatial and temporal resolution comparable to that of the model. In particular, basin-aggregated chlorophyll surface data produced by the OPATM-BFM in the period between April 2007 and September 2008 were compared with MODIS satellite data supplied by ISAC-CNR. The more significant outcomes from this comparison are outlined below:

- the model reproduces the seasonal variability of the surface chlorophyll in the Mediterranean basin, characterized by lower concentrations in the Summer and higher during the late Winter, showing a Spearman correlation with satellite data equal to 0.7 ;

- in Summer the OPATM-BFM median and variability is in good agreement with MODIS data, while during the September-February semester the model tends to overestimate the satellite evaluation;

- the onset of the chlorophyll Winter growth over the entire Mediterranean basin takes place earlier in the simulation than in the satellite data;

- at a sub-basin scale, the range of variability of surface chlorophyll is well reproduced by the model better in the north-western Mediterranean Sea than in the eastern basin, the latter being characterized by a significant overestimation of satellite data;
- model variability does not change throughout the period analysed for both the sub-basins, whilst satellite data show an increase in variability during Spring, especially in the north-western Mediterranean, possibly related to Spring bloom events;

- the model is able to forecast the dynamics (timing, location and intensity) of chlorophyll bloom related events during the simulation period in the Gulf of Lions consistently with the satellite observations.

The model has some drawbacks in the simulation of surface chlorophyll values when looking at large scale average, and it is possible that they are related to the absence of a temperature-dependent formulation. However, the capability of the model to correctly reproduce local events seems to be independent from the large scale inaccuracy, thus the system implemented can be considered a useful and reliable instrument for providing short-term forecasts of Mediterranean biogeochemistry in an operational setting.

A full assessment of system performance is planned in the near future, since at least two years of model outputs and satellite observations can provide time-series for sound statistical indicators.

To improve the model results, more information, such as time-dependent extinction coefficient obtained from satellite measurements and/or a data assimilation scheme for the biogeochemical compartment, are due to be introduced into the system, as has already been carried out for the Eastern 
Mediterranean Sea (Triantafyllou et al., 2007). This is planned to be implemented in the following development into a fully operational system, as required in MyOcean project.

Improvements of the model will focus on the following aspects:

1. integration of a time-dependent extinction coefficient provided by satellite measurements to improve the current solution based on a longitudinal, climatological extinction coefficient (Crispi et al., 2002);

2. implementation of data assimilation for surface chlorophyll, which will provide the possibility to enrich the model with satellite observed data;

3. porting of the entire system on a new facility hosted at CINECA together with the implementation of strict quality control that will also contribute to standardizing the whole procedure.

The system presented here is the result of the efforts carried out during MERSEA-IP, and will be further developed within MyOcean program according to the points mentioned above.

\section{Appendix A}

In this appendix the detailed formulation of the quantities used in the target diagrams of Fig. 10 are provided. Normalized unbiased root mean square difference (RMSD*' ${ }^{\prime}$ ):

$$
\begin{aligned}
\operatorname{RMSD}^{*^{\prime}}= & \frac{1}{\sigma_{r}}\left(\frac{1}{\mathrm{~N}} \sum_{n=1}^{\mathrm{N}}\left[\left(m_{n}-\bar{m}\right)-\left(r_{n}-\bar{r}\right)\right]^{2}\right)^{0.5} \\
& \operatorname{sign}\left(\sigma_{m}-\sigma_{r}\right)
\end{aligned}
$$

Normalized bias $\mathrm{B}^{*}$ :

$\mathrm{B}^{*}=\frac{\bar{m}-\bar{r}}{\sigma_{r}}$

Normalized root mean square difference (RMSD*):

$\mathrm{RMSD}^{*}=\frac{1}{\sigma_{r}}\left[\frac{1}{\mathrm{~N}} \sum_{n=1}^{\mathrm{N}}\left(m_{n}-r_{n}\right)^{2}\right]^{0.5}$.

In (Eqs. A1 and A2) $m_{n}$ and $r_{n}$ indicate the model and satellite base-10 logarithm of chlorophyll concentrations. The logarithm function maps model and satellite concentrations numerical values from the positive axis $\left(\mathfrak{R}^{+}\right)$to the whole axis $(\Re)$, thus the resulting vectors $m_{n}$ and $r_{n}$, fulfil the RMSD* formulation requirements. The over-bar represents the mean, $\mathrm{N}$ is the total amount of realizations, and $\sigma$ is the root mean square calculated for the two data sets. For any further detail please refer to Jolliff et al. (2009).
Acknowledgements. This work was partially co-founded by MERSEA-IP FP6 European project (www.mersea.eu.org/) and by the Italian VECTOR program (vector-conisma.geo.unimib.it/).

The authors wish to thank Nadia Pinardi for the warm encouragement and suggestions and Laurent Mortier for his friendly support and useful discussions.

Edited by: L. Bertino

\section{References}

Allen, J. I., Somerfield, P. J., and Siddorn, J.: Primary and bacterial production in the Mediterranean Sea: a modelling study, J. Marine Sys., 33-34, 437-495, 2002.

Baretta-Bekker, J. G.: Neth. J. Res., 33, Elsevier, Netherlands, 1995.

Baretta-Bekker, J. C., Baretta, J. W., and Ebenhoh, W.: Microbial dynamics in the marine ecosystem model ERSEMII with decoupled carbon assimilation and nutrient uptake, Jou. Sea Res., 153, 251-261, 1997.

Behrenfeld, M. J., Prasil, O., Babin, M., and Bruyant, F.: In search of a physiological basis for covariations in light-limited and light-saturated photosynthesis, J. Phycol., 40, 4-25, 2004.

Bosc, E., Bricaud, A., and Antoine, D.: Seasonal and interannual variability in algal biomass and primary production in the Mediterranean Sea, as derived from 4 years of SeaWiFS observations, Global Biogeochem. Cy., 18, GB1005, doi:10.1029/2003GB002034, 2004.

Crise, A., Crispi, G., and Mauri, E.: A seasonal three-dimensional study of the nitrogen cycle in the Mediterranean Sea Part I. Model implementation and numerical results, J. Marine Sys., 18, 287-312, 1998.

Crise, A., Solidoro, C., and Tomini, I.: Preparation of initial conditions for the coupled model OGCM and initial parameters setting, MFSTEP report WP11, subtask 11310, 2003.

Crispi, G., Crise, A., and Solidoro, C.: Coupled Mediterranean ecomodel of the phosphorus and nitrogen cycles, J. Marine Sys., 33-34, 497-521, 2002.

Dobricic, S., Pinardi, N., Adani, M., Tonani, M., Fratianni, C., Bonazzi, A., and Fernandez, V.: Daily oceanographic analyses by Mediterranean Forecasting System at the basin scale, Ocean Sci., 3, 149-157, 2007, http://www.ocean-sci.net/3/149/2007/.

Flemming, N. C., Vallerga, S., Pinardi, N., Behrens, H. W. A., Manzella, G., Prandle, D., and Stel, J. H.: Operational Oceanography - Implementation at the European and Regional Scales, Elsevier Oceanography, Vol. 66, Elsevier, Amsterdam, 572 pp. 2002.

Geider, R. J., MacIntyre, H. L., and Kana, T. M.: Dynamic model of phytoplankton growth and acclimation: responses of the balanced growth rate and the chlorophyll a: carbon ratio to light, nutrient-limitation and temperature, Mar. Ecol.-Prog. Ser., 148, 187-200, 1997.

Guerzoni, S., Chester, R., Dulac, F., Herut, B., Loÿe-Pilot, D., Measures, C., Migon, C., Molinaroli, E., Moulin, C., Rossini, P., Saydam, C., Soudine, A., and Ziveri, P.: The role of atmospheric de- 
position in the biogeochemistry of the Mediterranean Sea, Prog. Oceanogr., 44, 147-190, 1999.

Johannessen, J. A., Le Traon, P.-Y., Robinson, I., Nittis, K., Bell, M. J., Pinardi, N., and Bahurel, P.:. Marine Environment and Security for the European Area - Toward Operational Oceanography, B. Am. Meteorol. Soc., 87, 1081-1090, 2006.

Jolliff, J. K., Kindle, J. C., Shulman, I., Penta, B., Friedrichs, M. A. M., Helbert, R., and Arnone, R. A.: Summary diagrams for coupled hydrodynamic-ecosystem model skill assessment, J. Marine Sys., 76(1-2), 64-82, 2009.

Lazzari, P. and Crise, A.: Sensitivity Analysis Results, MERSEAIP Deliverable D11.2.2.1, 20 pp., 2006.

Lazzari, P., Salon, S., and Crise, A.: A massively parallel off-line transport model designed to be coupled with OPA and BFM, MERSEA-IP Deliverable D11.2.1.1, 16 pp., 2005.

Lazzari, P. and co-authors: The seasonal and inter annual variability of the Primary Productivity in the Mediterranean Basin: a modelling approach, in preparation, 2010.

Longhurst, A. R.: Ecological Geography of the Sea, Academic Press, Amsterdam. 398 pp., 2001.

Madec, G., Delecluse, P., Imbard, M., and Lévy, C.: OPA 8.1 Ocean General Circulation Model Reference Manual, Note n. 11, Laboratoire d'Océanographie DYnamique et de Climatologie, Institut Pierre Simon Laplace, Paris, France, 91 pp. 1998.

Mann, K. H. and Lazier, J. R. N.: Dynamics of Marine Ecosystem, Blackwell Scientific Publications Inc., Boston, United States, 466 pp., 1991.

Moutin, T. and Raimbault, P.: Primary production, carbon export and nutrients availability in western and eastern Mediterranean Sea in early summer 1996 (MINOS cruise), J. Marine Sys., 3334, 273-288, 2002.

Nixon, S. W.: Replacing the Nile: Are Anthropogenic Nutrients Providing the Fertility Once Brought to the Mediterranean by a Great River?, AMBIO, 32, 30-39, 2003.

Palmeri, L., Bendoricchio, G., and Artioli, Y.: Modelling nutrient emissions from river systems and loads to the coastal zone: Po River case study, Italy, Ecol. Model., 184, 37-53, 2005.

Petihakis, G., Triantafyllou, G., Tsiaras, K., Korres, G., Pollani, A., Hoteit, I.: Eastern Mediterranean biogeochemical flux model - Simulations of the pelagic ecosystem, Ocean Sci., 5, 29-46, 2009 , http://www.ocean-sci.net/5/29/2009/.

Polimene, L., Pinardi, N., Zavatarelli, M., and Colella, S.: The Adriatic Sea ecosystem seasonal cycle: Validation of a threedimensional numerical model, J. Geophys. Res., 111, C03S19, doi:10.1029/2005JC003260, 2006.

Pinardi, N.: The Mediterranean Sea ocean variability and operational oceanography: a science based approach for sustainable development of marine and coastal areas, Geophysical Research Abstracts, 9, 11478, SRef-ID:1607-7962/gra/EGU2007A-11478, 2007.
Pinardi, N., Allen, I., Demirov, E., De Mey, P., Korres, G., Lascaratos, A., Le Traon, P.-Y., Maillard, C., Manzella, G., and Tziavos, C.: The Mediterranean ocean Forecasting System: first phase of implementation (1998-2001), Ann. Geophys., 21, 3-20, 2003 , http://www.ann-geophys.net/21/3/2003/.

Pinardi, N., Manzella, G., Coppini, G., Bahurel, P., and Downbrowsky, E.: Mediterranean Operational Oceanography Network (MOON) - Science and Strategy Plan, Mediterranean Operational Oceanography Network (MOON) Memorandum of Understanding, www.moon-oceanforecasting.eu/, 2006.

Polat, S. C., Turul, S., oban, Y., Basturk, O., and Salihoglu, I.: Elemental composition of seston and nutrient dynamics in the Sea of Marmara, Hydrobiologia, 363, 157-167, 1997.

Ribera d'Alcalà, M., Civitarese, G., Conversano, F., Lavezza, R.: Nutrient ratios and fluxes hint at overlooked processes in the Mediterranean Sea, J. Geophys. Res., 108(C9), 8106, doi:10.1029/2002JC001650, 2003.

Santoleri, R., Volpe, G., Marullo, S., Buongiorno Nardelli, B.: Open Waters Optical Remote Sensing of the Mediterranean Sea, in: "Remote Sensing of the European Seas", edited by: Barale, V., and Gade, M., Springer, 103-114, 2008.

Smolarkiewicz, P. K.: A simple positive definite advection scheme with small implicit diffusion, Mon. Weather Rev., 111, 479-486, 1983.

Thingstad T. F. and Rassoulzadegan, F.: Nutrient limitations, microbial food webs, and "biological C-pumps": suggested interactions in a P-limited Mediterranean, Mar. Ecol.-Prog-Ser., 117, 299-306, 1995.

Tonani, M., Pinardi, N., Dobricic, S., Pujol, I., and Fratianni, C.: A high-resolution free-surface model of the Mediterranean Sea, Ocean Sci., 4, 1-14, 2008, http://www.ocean-sci.net/4/1/2008/.

Triantafyllou, G., Korres, G., Hoteit, I., Petihakis, G., and Banks, A. C.: Assimilation of ocean colour data into a Biogeochemical Flux Model of the Eastern Mediterranean Sea, Ocean Sci., 3, 397-410, 2007, http://www.ocean-sci.net/3/397/2007/.

Varela, R. A., Cruzado, A., and Gabaldon, J. E.: Modelling primary production in the North Sea using the European Regional Seas Ecosystem Model, Neth. J. Sea Res., 33, 337-361, 1995.

Vichi, M., May, W., and Navarra, A.: Response of a complex ecosystem model of the northern Adriatic Sea to a regional climate change scenario, Clim. Res., 24, 141-159, 2003.

Vichi, M., Pinardi, N., and Masina, S.: A generalized model of pelagic biogeochemistry for the global ocean ecosystem, Part I: Theory, J. Marine Sys., 64, 89-109, 2007a.

Vichi, M., Masina, S., and Navarra, A.: A generalized model of pelagic biogeochemistry for the global ocean ecosystem, Part II: Numerical Simulations, J. Marine Sys., 64, 110-134, 2007 b. 